\title{
Lupus/Sjögren's Autoantibody Specificities in Sera with Paraproteins
}

Andrea L. Sestak, John B. Harley, Sunji Yoshida, and Morris Reichlin

Department of Medicine, University of Oklahoma Health Sciences Center; Arthritis and Immunology Research Program,

Oklahoma Medical Research Foundation; and Veterans Administration Hospital, Oklahoma City, Oklahoma 73104

\begin{abstract}
Antinuclear antibody and anti-RNA-protein autoantibodies were determined in 143 sera containing paraproteins and 39 control sera. Antinuclear antibodies were commonly present in the paraprotein sera by indirect immunofluorescence. 19 of 143 sera (13\%) had elevated anti-Ro/SSA activity in a solid phase Ro/ SSA binding assay, and 5 (3.5\%) had Ro/SSA precipitating autoantibody. Eighteen sera had La/SSB binding autoantibodies (12\%) but only one had an anti-La/SSB precipitin. AntinRNP(Sm) was not detected in any of these sera.

The solid phase anti-RNA protein assays were repeated using anti- $\lambda$ and anti- $\kappa$ conjugates. Both $\lambda$ and $\alpha$ light chain autoantibodies were found in all positive sera consistent with polyclonal anti-Ro/SSA and anti-La/SSB responses. Paraprotein sera containing Ro/SSA precipitins were analyzed by isoelectric focusing followed by exposure to ${ }^{125} \mathrm{I}$-labeled Ro/SSA and autoradiography. All sera with anti-Ro/SSA binding paraproteins also contained polyclonal anti-Ro/SSA. Our data are consistent with the hypothesis that anti-Ro/SSA paraproteins are common and arise from a previously present polyclonal anti-Ro/SSA response.
\end{abstract}

\section{Introduction}

The known specificities of myeloma proteins include a remarkable number of autoantigens, such as rheumatoid factor, blood group antigens, lipoproteins, serum albumin, peripheral nerve myelin, cytoskeletal proteins, and DNA. Antibodies to haptens and bacterial antigens have also been characterized, and several of these also bind to DNA or polyclonal IgG (1-3). However, even after $35 \mathrm{yr}$ of intense investigation into the structure and function of human myeloma proteins, the specific reactivities of the majority of myeloma immunoglobulins remain unknown.

Antibodies to a group of nonribosomal small RNA protein molecules are common in systemic lupus erythematosus, Sjögren's syndrome, and other rheumatic disorders and are among the autoimmune specificities that may be present in very high concentrations in some sera (4-7). These RNA protein particles are known as Ro/SSA, La/SSB, nRNP and Sm. Ro/SSA consists of a $60-\mathrm{kD}$ peptide and one of four RNAs from 84 to 112 bases $(8,9)$. The $\mathrm{La} / \mathrm{SSB}$ protein is $43 \mathrm{kD}$ and binds a number of RNAs, all of which have multiple uridine bases at the $3^{\prime}$ end $(10,11)$. The Ro/SSA and La/SSB RNAs are generally RNA polymerase III products (12). Sm and nRNP particles contain the $U$ RNAs ( $U$ indicating their high uridine content). The five

Address reprint requests to Dr. Reichlin.

Received for publication 21 October 1986 and in revised form 30 January 1987.

J. Clin. Invest.

(c) The American Society for Clinical Investigation, Inc.

$0021-9738 / 87 / 07 / 0138 / 07 \$ 2.00$

Volume 80, July 1987, 138-144
U RNAs variably bind a set of peptides, some of which carry specificities for $n R N P$ and $\operatorname{Sm}\left(U_{1}\right)$ and others $\left(U_{2}, U_{4}, U_{5}\right.$, and $U_{6}$ ) that carry only the Sm specificity (13). The $U_{1}$ particle is the only one of these RNA proteins whose function is known. It contains a consensus sequence with the splice junctions of heteronuclear RNA and appears to be an important cofactor in removing introns to generate messenger RNA $(14,15)$.

The appreciation that some sera containing paraproteins have had anti-Ro/SSA activity, the realization that most of the known specificities of myeloma proteins are autoantigens, and the finding that anti-Ro/SSA and anti-La/SSB are commonly found at low levels in normal healthy individuals $(5,16)$ led us to assess the frequency of these autoantibodies in sera with paraproteins and to characterize their reactivity. This analysis revealed that paraprotein sera commonly contained antinuclear antibodies. In addition, there was a high frequency of binding to Ro/SSA while anti-nRNP(Sm) activity was not found in these sera. Efforts to define the antibody population reacting with Ro/SSA showed that in each case analyzed a polyclonal anti-Ro/SSA response was present. In some Ro/SSA precipitin sera, the paraprotein also bound Ro/SSA, while in others it did not.

\section{Methods}

Sera. The sera from 143 patients with paraproteins were prospectively collected from specimens for which immunoelectrophoresis was requested at the Clinical Immunology Laboratory of the State University of New York at Buffalo. Entry to this study required only the presence of a paraprotein and, therefore, available clinical data were incomplete in many patients. From the cohort with adequate clinical data, it is estimated that $60 \%$ of these patients had multiple myeloma or Waldenstrom's macroglobulinemia while the remainder had a benign monoclonal gammopathy. Two of these patients had systemic lupus erythematosus (17) and a benign monoclonal gammopathy. Normal control sera were collected from 39 students, laboratory workers, and other colleagues. All sera were stored at $-20^{\circ} \mathrm{C}$ for 2 yr or more.

Autoantibody assays. Precipitins against Ro/SSA, La/SSB, nRNP and $\mathrm{Sm}$ were detected by Ouchterlony gel diffusion using human spleen and rabbit thymus extracts as sources of antigen. Tests for antinuclear antibodies were performed on mouse kidney frozen sections and KB tissue cell culture substrates.

The myeloma sera and 39 normal controls were screened for antiRo/SSA, anti-La/SSB, and anti-nRNP(Sm) using solid-phase enzymelinked immunosorbent assay (ELISAs) ${ }^{1}$ as reported in previous studies $(5,6,18)$. Briefly, in the anti-Ro/SSA and anti-nRNP(Sm) assays, the plates were coated with affinity purified antigen from bovine spleen extract (BSE) and blocked with bovine serum albumin (BSA) before sample application. Specific activity was determined by preincubating duplicate samples with $30 \mu \mathrm{g} / \mathrm{ml} \mathrm{Ro/SSA}$ or $10 \mu \mathrm{g} / \mathrm{ml} \mathrm{nRNP}(\mathrm{Sm})$, respectively. In the anti-La/SSB ELISA, the plate was coated with anti-Lal monoclonal $\mathrm{F}\left(\mathrm{ab}^{\prime}\right)_{2}$ fragments, blocked, and charged with Ro/SSA depleted BSE (18). Background was determined by comparison with duplicate wells charged

1. Abbreviations used in this paper: BSE, bovine spleen extract; ELISA, enzyme-linked immunosorbent assay; SLE, systemic lupus erythematosus. 
with a La/SSB depleted extract. Goat anti-human IgG alkaline phosphatase conjugate (Sigma Chemical Co., St. Louis, MO) was added after sample application. The plates were developed with $p$-nitrophenyl phosphate and read using a MR-580 Microelisa reader (Dynatech Laboratories, Inc., Alexandria, VA). The optical density developed by a $10^{-7}$ dilution of a precipitin positive reference sera was defined as one unit of binding. In the anti-Ro/SSA assay, one unit of binding has been shown to be equivalent to the anti-Ro/SSA activity of $\sim 200 \mathrm{pg} / \mathrm{ml}$ of specifically purified anti-Ro/SSA (5). After the initial screening, anti-human IgA and anti-human IgM conjugates were used to screen patients of those paraprotein types. In addition, these conjugates were used to characterize the heavy chain type(s) of the binding antibodies; similarly, anti-human kappa and lambda light chain reagents were used to determine the light chain types. Specificity of these conjugates was confirmed using purified reagents collected and prepared in our laboratory.

Isoelectric properties. of Ro/SSA binding immunoglobulin. An isoelectric focusing technique was developed to determine whether an individual myeloma protein bound Ro/SSA. Serum samples were run undiluted on Ampholine PAGplate pH 3.5-9.5 (LKB Instruments, Stockholm, Sweden) or $0.8 \%$ agarose $/ 0.3 \%$ acrylamide immunoelectrophoresis gels at $4^{\circ} \mathrm{C}$ for $2 \mathrm{~h}$ at $1,500 \mathrm{~V}$. Immunoglobulins were precipitated using $21 \%$ sodium sulfate. The gels were washed twice in $18 \%$ sodium sulfate and blocked for $1 \mathrm{~h}$ with $1 \% \mathrm{BSA}$, and the precipitated antibodies were photographed. The gels were then exposed to ${ }^{125}$ I-labeled Ro/SSA in blocking solution overnight, followed by washing for $24 \mathrm{~h}$ with three changes of the wash buffer. Ro/SSA antigen was radiolabeled with ${ }^{125} I$ by the Iodogen method according to manufacturer's instructions (Pierce Chemical Co., Rockford, IL). The immune complexes were cross-linked with $0.1 \%$ glutaraldehyde for $1 \mathrm{~h}$ at room temperature, then the gels were dried. The dried gels were exposed to x-ray film for 18-24 h to detect the bands that bound the radiolabeled Ro/SSA. The autoradiographs were compared to photographs of the sodium sulfate precipitated immunoglobulin from the same gel to determine whether a paraprotein had anti-Ro/SSA binding.

Data analysis. In the ELISA assay, specific binding of each serum has been determined as the difference in activity before and after preincubation with antigen in the anti-Ro/SSA and anti-nRNP(Sm) assays, or the difference in wells charged with extract containing or depleted of $\mathrm{La} / \mathrm{SSB}$. The values presented are the log average of the results of two or more determinations. In the anti-Ro/SSA and anti-nRNP(Sm) assays, binding below $1 \mathrm{U}$ could not be detected; since the sera were screened at a dilution of 1:250, the lowest level recorded is $250 \mathrm{U}$. The anti-La/ SSB assay is at least 10-fold more sensitive than the other ELISAs (18), so the limit of sensitivity for this assay was set at $25 \mathrm{U}$.

In the anti-Ro/SSA assay, a sample was considered positive if it had $>10,000 \mathrm{U}$ of specific binding and $>50 \%$ specific inhibition. This limit was established in previous studies of normal sera when anti-Ro/SSA specific antibody was isolated from normal sera having this binding activity $(5-8,18-20)$. In the anti-La/SSB and anti-nRNP(Sm) assays, sera were considered positive if they had activity over two standard deviations above the mean of the normal sera with $>50 \%$ specific inhibition. This level corresponds to $1,000 \mathrm{U}$ in the $\mathrm{La} / \mathrm{SSB}$ assay and 10,000 $\mathrm{U}$ in the $\mathrm{nRNP}(\mathrm{Sm})$ assay. Analytical tests used included Student's $t$ test, chisquare with Yates' correction, Fisher exact test (two-tailed), Wilcoxon rank sum test, and Spearman rank correlation test. $P<0.05$ was considered statistically significant. Degrees of freedom were recalculated using Satterthwaite's adjustment when groups of unequal variance were tested in Student's $t$ test.

\section{Results}

Antinuclear antibodies. The 143 sera containing paraproteins and a group of 39 normal sera were screened for antinuclear antibodies at a dilution of 1:250 on mouse kidney and $\mathrm{KB}$ cell substrates. None of the normals had positive fluorescence on either substrate at this dilution. On the mouse kidney substrate, 13 of the 143 paraprotein sera had antinuclear antibodies. Nu- clear antigens were bound by 10 sera; 5 of these had a homogenous pattern, 2 were speckled, 1 bound the nuclear membrane, and 2 also bound the nucleolus. Seven of the positive sera were at endpoint at the 1:250 screening dilution, but in the others the antinuclear antibody test using mouse kidney tissue ranged to a high titer of 1:6750. Three sera bound cytoplasmic antigens in the mouse kidney sections. All 13 sera also bound KB cells, although many had different titers and patterns.

When KB cells were used as the antinuclear antibody substrate, over three times as many were found to be positive. Of 143 patients, 43 were positive at a dilution of $1: 250$, and 14 had activity at higher titers, to $1: 6,750$ for one patient. Most sera displayed homogenous nuclear fluorescence, but four were nucleolar, three were speckled, and eight were cytoplasmic. Two sera bound both the nucleus and the nucleolus, and one serum had both nuclear and cytoplasmic fluorescence. The highest titer serum had a cytoplasmic pattern at 1:6,750 and did not bind mouse kidney tissue sections.

Anti-Ro/SSA autoantibody. Anti-Ro/SSA precipitins were found in five of the 143 sera (3.5\%), and these five sera also had the highest levels of binding to Ro/SSA in the solid phase assay. 14 additional sera had lower levels of positive anti-Ro/SSA binding. There was a total of 19 anti-Ro/SSA positive sera, which had a mean of 63,460 anti-Ro/SSA units of binding, and seven positive normal sera, which had a mean of 14,686 U (Fig. 1). While the positive patients had greater Ro/SSA binding than the positive controls, most of the patients had significantly less binding than did the normal control sera (Table I).

Anti-La/SSB and anti-nRNP(Sm) autoantibodies. An anti$\mathrm{La} / \mathrm{SSB}$ precipitin was found in one patient. This patient had the highest average level of binding in the anti-La1 ELISA and was additionally positive for both anti-Ro/SSA and antinuclear antibody. 18 patients had over $1,000 \mathrm{U}$ of anti-La/SSB specific binding and were therefore considered positive in this assay (Fig. 1), and these patients had an average of 3,486 $\mathrm{U}$ of anti-La/SSB activity. There was only one positive normal, with $2,157 \mathrm{U}$ of anti-La/SSB binding. Overall, normals had more anti-La/SSB than patients ( $217 \mathrm{U}$ vs. $174 \mathrm{U}$ anti-La/SSB), even though a much greater percentage of the patients were positive.

In the anti-nRNP(Sm) assay, no positives were found in either population (Fig. 1). This fact is significant since several positive sera were found in the other anti-RNA-protein solid phase assays. As in the other solid phase assays, the normals had significantly higher average levels of binding than did the patients (Table I).

Relationships between autoantibodies. Many relationships have been found between the various assays used in this study (Table II). Of the 60 sera positive in at least one assay, 14 are
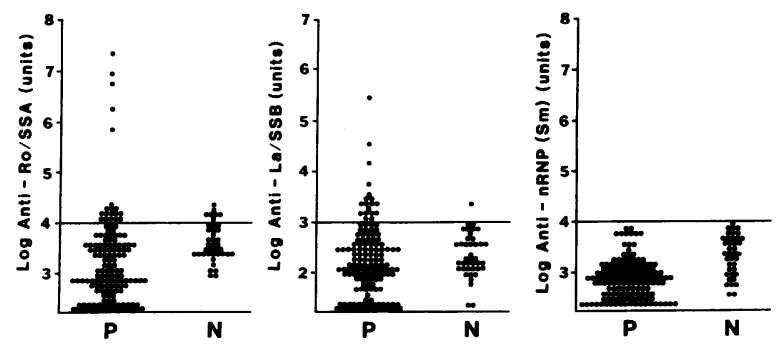

Figure 1. Anti-RNA-protein activity in 143 paraprotein sera $(\mathrm{P})$ and 39 normal control sera $(\mathrm{N})$. Data are presented as the $\log _{10}$ of the binding units observed in a solid phase assay using purified Ro/SSA, $\mathrm{La} / \mathrm{SSB}$, and $\mathrm{nRNP}(\mathrm{Sm})$. 
Table I. Normal Sera Have More Average ELISA Binding Than Sera with Paraproteins

\begin{tabular}{llll}
\hline & \multicolumn{2}{l}{ Average anti-RNA protein binding* } & \\
\cline { 2 - 3 } Assay & Normals & \multicolumn{1}{l}{ Patients } & \multicolumn{1}{c}{$P^{*}$} \\
\hline & \multicolumn{1}{l}{$U$} & \\
& & & \\
Anti-Ro/SSA & $3,964 \times / \div 1.17$ & $1,722 \times / \div 1.36$ & 0.0005 \\
Anti-La/SSB & $217 \times / \div 1.17$ & $174 \times / \div 1.28$ & 0.2837 \\
Anti-nRNP(Sm) & $2,083 \times / \div 1.16$ & $729 \times / \div 1.14$ & 0.0001 \\
& & & \\
\hline
\end{tabular}

* Values presented represent the anti-log of the $\log _{10}$ average binding units found in 39 normal subjects and 143 myeloma patients. $X / \div$ standard error of the mean.

${ }^{\ddagger} \boldsymbol{P}$ was determined by Student's $t$ test. In the anti-Ro/SSA and anti$\mathrm{La} / \mathrm{SSB}$ assays, the two groups have unequal variance, and Satterthwaite's adjustment for degrees of freedom has been used.

positive in at least two assays, six in three assays, and two in four assays. Of the 18 sera positive for anti-Ro/SSA, eight are also positive for anti-La/SSB $(P<0.001)$. Spearman rank correlation of the entire population confirms the relationship between anti-Ro/SSA and anti-La/SSB $(r=0.28, P=0.0008)$. Chi-square analysis shows relationships between anti-La/SSB and antinuclear antibodies, Ro/SSA precipitins and antinuclear antibodies, and Ro/SSA precipitins and anti-La/SSB. Of the eight sera positive for both anti-Ro/SSA and anti-La/SSB, six have nuclear immunofluorescence $(P=0.009)$. Although no positives are found in the $\mathrm{nRNP}(\mathrm{Sm})$ assay, there are only 20 sera that have no detectable binding, and these sera are surprisingly active in the other assays. This group includes the five Ro/SSA precipitin sera (but none of the other anti-Ro/SSA positives; $P$ $<0.0001$, Fisher exact test), six sera positive for anti-La/SSB, and 10 sera with antinuclear antibodies.

Relationships of autoantibodies to paraprotein types. There is a clear difference in the average activity of sera grouped by paraprotein type, especially when grouped by light chain. Of the 143 patients in this study, 86 have $\kappa$ paraproteins, 53 have $\lambda$, and four have paraproteins with no identifiable light chain. Four of the five Ro/SSA precipitin sera have a $\lambda$ light chain paraprotein including the one serum containing a La/SSB precipitin.

Sera with reactivity in two or more of the autoantibody assays were more likely to have $\lambda$ paraproteins (Table III). For example, of the sera with antinuclear antibodies, 16 have $\lambda$ and 24 have $\kappa$ light chain paraproteins. In the group of sera positive for both anti-Ro/SSA and antinuclear antibody, six have $\lambda$ light chain paraproteins and three have $\kappa$. Of the six sera containing antiRo/SSA, anti-La/SSB, and antinuclear antibody, five have $\lambda$ paraproteins $(P=0.030$, Fisher exact test). 8 of the $18 \mathrm{La} / \mathrm{SSB}$ positive sera are $\lambda$, and seven of these also have positive antinuclear fluorescence; comparatively, only one $\kappa$ serum reacts in both the anti-La/SSB and ANA assays $(P=0.005$, Fisher exact test).

Comparisons of sera categorized by light chain type in Wilcoxon rank sum tests confirm the impression that sera with $\lambda$ light chain paraproteins have increased autoantibody activity; the rank difference in the groups defined by light chain type is evident in the anti-La/SSB assay and is nearly significant in the anti-Ro/SSA assays $(P=0.035$ and 0.068 , respectively). This difference between light chain types in the paraprotein sera is more pronounced among patients with IgG paraproteins, particularly in the anti-Ro/SSA assay $(P=0.013)$. There is no significant difference between the two light chain groups in either the antinuclear antibody assay or in the anti-nRNP(Sm) assay.

Autoimmune reactivity of paraproteins. The next objective of the study was to determine the heterogeneity of the antibodies responsible for the autoimmune activity. The original ELISA assays, designed to detect only IgG, were modified by using conjugates directed against $\operatorname{IgA}$, IgM, and the $\kappa$ and $\lambda$ light chains. The sera with IgA and IgM paraproteins were retested using the corresponding conjugates, but the only reactive sera were those that had been previously detected with the anti-IgG conjugate. Sera with previously detected IgG autoimmune activity were retested with the other four conjugates. Many sera had additional heavy chain activity, and most sera were reactive with both light chain conjugates. This data suggested that autoimmune reactivity did not necessarily correspond to and hence may not be directly related to the paraproteins or their reactivities.

The five Ro/SSA precipitin positive sera were studied in particular detail to determine whether or not the paraproteins contributed to the autoimmune activity. All five sera had high levels of IgG directed against Ro/SSA (Table IV). In addition, patient 2 , who had a $\lambda$ light chain Waldenstrom's macroglobulin, had both $\gamma$ - and $\mu$-chain activity against both Ro/SSA and La/SSB in ELISA. The isolated macroglobulin from this patient neither bound Ro/SSA in ELISA nor formed a precipitin, strongly suggesting that other immunoglobulins must be responsible for the binding activity. In patient 1 , who had a $\lambda \operatorname{IgA}$ paraprotein, the $\alpha$-chain conjugate detected no anti-Ro/SSA activity, implying

Table II. Relationships between Autoantibodies in 143 Sera Containing Paraproteins

\begin{tabular}{lllllr}
\hline Test A & $\begin{array}{l}\text { Number } \\
\text { positive }\end{array}$ & Test B & $\begin{array}{l}\text { Number } \\
\text { positive }\end{array}$ & $\begin{array}{l}\text { Number } \\
\text { positive in tests } \\
\text { A and B }\end{array}$ \\
\hline Ro/SSA & 19 & La/SSB & 18 & 8 & $P^{*}$ \\
Ro/SSA & 19 & ANA & 43 & 9 & 0.106 \\
La/SSB & 18 & ANA & 43 & 9 & 0.058 \\
Ro/SSA and La/SSB & 8 & ANA & 43 & 6 & 0.009 \\
Ro/SSA precipitin & 5 & ANA & 43 & 5 & 0.002 \\
Ro/SSA precipitin & 5 & La/SSB & 18 & 4 & 0.001
\end{tabular}

* $P$ was determined by two-tailed Fisher exact test. ELISA results are presented unless precipitin is indicated. ${ }^{*}$ ANA indicates an antinuclear antibody on a KB substrate. 
Table III. Relations between Autoantibodies and Light Chain Types of Paraproteins

\begin{tabular}{|c|c|c|c|}
\hline \multirow[b]{2}{*}{ Autoantibody tests } & \multicolumn{2}{|c|}{$\begin{array}{l}\text { Paraprotein } \\
\text { light chain } \\
\text { (number positive) }\end{array}$} & \multirow[b]{2}{*}{$P^{*}$} \\
\hline & ж & $\lambda$ & \\
\hline None (total population) & $86(60 \%)$ & $53(38 \%)$ & \\
\hline Anti-Ro/SSA & 8 & 10 & 0.122 \\
\hline Anti-La/SSB & 9 & 8 & 0.435 \\
\hline ANA $^{\ddagger}$ & 24 & 16 & 0.848 \\
\hline Anti-Ro/SSA, anti-La/SSB & 2 & 5 & 0.105 \\
\hline Anti-Ro/SSA, ANA & 3 & 6 & 0.084 \\
\hline Anti-La/SSB, ANA & 1 & 7 & 0.005 \\
\hline Anti-Ro/SSA, anti-La/SSB, ANA & 1 & 5 & 0.030 \\
\hline
\end{tabular}

* $P$ determined by two-tailed Fisher exact test. ELISA results are compared.

${ }^{\ddagger}$ ANA indicates an antinuclear antibody determined on a KB substrate.

that the paraprotein did not bind Ro/SSA and, therefore, requiring that the activity observed was present in other immunoglobulins. All five sera had high levels of binding activity with both light chain conjugates in both the anti-Ro/SSA and anti$\mathrm{La} / \mathrm{SSB}$ assays. Therefore, while in three of five cases the paraprotein may bind Ro/SSA (or La/SSB), the response to these antigens must be polyclonal.

Analysis of serum proteins by isoelectric focusing followed by binding to radiolabeled Ro/SSA provided a direct method of observing the heterogeneity of the immunoglobulin binding Ro/ SSA (Fig. 2). Although the paraproteins of patients with cryoprecipitins were not visible in this assay, and therefore no conclusions could be reached about the paraprotein binding activity of patients 1 and 2, heterogeneous activity was clearly present in all five Ro/SSA precipitin sera (Fig. 2) reinforcing the conclusion from the solid phase assays that these responses were at least polyclonal. In addition, the binding of radiolabeled Ro/ SSA to sera from patients 4 and 5 clearly accentuated their paraprotein bands (Fig. 2, lanes 2 and 3), indicating that these paraproteins must bind Ro/SSA. Paraprotein sera without anti-Ro/ SSA binding did not exhibit either the heterogeneous polyclonal binding or binding by their paraproteins as illustrated by the serum in lane 6 . Although only one such serum is illustrated, similarly negative results were obtained with nine other paraprotein sera that lacked anti-Ro/SSA binding by ELISA. Serum from patient 3 demonstrated a polyclonal response, but the myeloma protein in this serum did not bind the radiolabeled Ro/ SSA (Fig. 2, lane 5). Interestingly, clinical records on these patients showed that 4 and 5 actually had systemic lupus erythematosus with a benign monoclonal gammopathy while the other three patients had multiple myeloma or Waldenstrom's macroglobulinemia without evidence of an autoimmune disease.

\section{Discussion}

In this study, we found that certain autoantibodies found in systemic lupus erythematosus are also found in patients with paraproteins. Almost one third of the sera tested had high titers of antinuclear antibodies, and more than $20 \%$ had increased levels of antibody binding to Ro/SSA and/or La/SSB, but none of the sera had antibodies to nRNP(Sm). Anti-Ro/SSA and anti$\mathrm{La} / \mathrm{SSB}$ antibodies were related to one another and to the presence of antinuclear antibodies. Patients with $\lambda$ light chain paraproteins tended to have more anti-Ro/SSA and anti-La/SSB activity than patients with $\kappa$ light chain paraproteins.

Solid phase assays using $\lambda$ and $\kappa$ light chain specific conjugates showed that in each positive serum, antibodies of both light chain types bound Ro/SSA or La/SSB. To confirm this finding of apparent polyclonality and to determine whether the paraprotein bound Ro/SSA in addition to the polyclonal antibodies, isoelectric focusing was performed and the antibodies binding to Ro/SSA revealed by autoradiography using ${ }^{125}$ I-labeled Ro/ SSA. This method confirmed that the paraprotein sera with antiRo/SSA activity had polyclonal anti-Ro/SSA autoantibodies. In addition, the paraprotein specificity of some of these sera (two of the three amenable to testing) was established by its binding to radiolabeled Ro/SSA. These studies confirmed earlier work suggesting that these paraproteins had anti-Ro/SSA activity. Native polyacrylamide gel electrophoresis had previously been used to isolate the paraproteins of patients 4 and 5 (Table IV) and the isolated paraproteins were shown to have Ro/SSA precipitin activity while the remaining immunoglobulin did not (Reichlin, M., unpublished data).

The frequency of paraproteins of various heavy and light chain types and electrophoretic mobilities parallels the frequency

Table IV. Anti-Ro/SSA Precipitin Sera Have Similar Reactivities in Other Assays

\begin{tabular}{|c|c|c|c|c|c|c|c|c|}
\hline \multirow[b]{2}{*}{ Patient } & \multirow[b]{2}{*}{ Diagnosis } & \multirow[b]{2}{*}{$\begin{array}{l}\text { Precipitating } \\
\text { autoantibody }\end{array}$} & \multicolumn{3}{|l|}{ IgG activity } & \multicolumn{2}{|l|}{ ANA* $^{*}$} & \multirow{2}{*}{$\begin{array}{l}\text { Paraprotein } \\
\text { type }\end{array}$} \\
\hline & & & Anti-Ro/SSA & Anti-La/SSB & Anti-nRNP (Sm) & $\mathbf{K B}$ & MK & \\
\hline & & & $U$ & $U$ & $U$ & titer & titer & \\
\hline 1 & Multiple myeloma & Ro/SSA & 755,000 & 2,070 & $<250$ & $1: 250$ & - & $\lambda \operatorname{IgA}$ \\
\hline 2 & $\begin{array}{l}\text { Waldenstrom's } \\
\text { macroglobulinemia }\end{array}$ & Ro/SSA & $5,940,000$ & 35,600 & $<250$ & $1: 2250$ & - & $\lambda \operatorname{IgM}$ \\
\hline 3 & Multiple myeloma & Ro/SSA & $1,610,000$ & 14,200 & $<250$ & $1: 250$ & $1: 250$ & $\lambda \operatorname{IgG}$ \\
\hline 4 & BMG and SLE $^{\ddagger}$ & Ro/SSA & $8,660,000$ & 253,000 & $<250$ & $1: 1,000$ & $1: 1,000$ & $\lambda \operatorname{IgG}$ \\
\hline 5 & BMG and SLE & Ro/SSA & $20,500,000$ & 767 & $<250$ & $1: 1,000$ & $1: 1,000$ & $\kappa I g G$ \\
\hline
\end{tabular}

* ANA indicates antinuclear antibody on a KB tissue culture cell or mouse kidney (MK) tissue section substrate. ${ }^{\ddagger}$ BMG indicates a patient who had a benign monoclonal gammopathy. SLE indicates that patients fulfilled criteria for the diagnosis of systemic lupus erythematosus (17). 


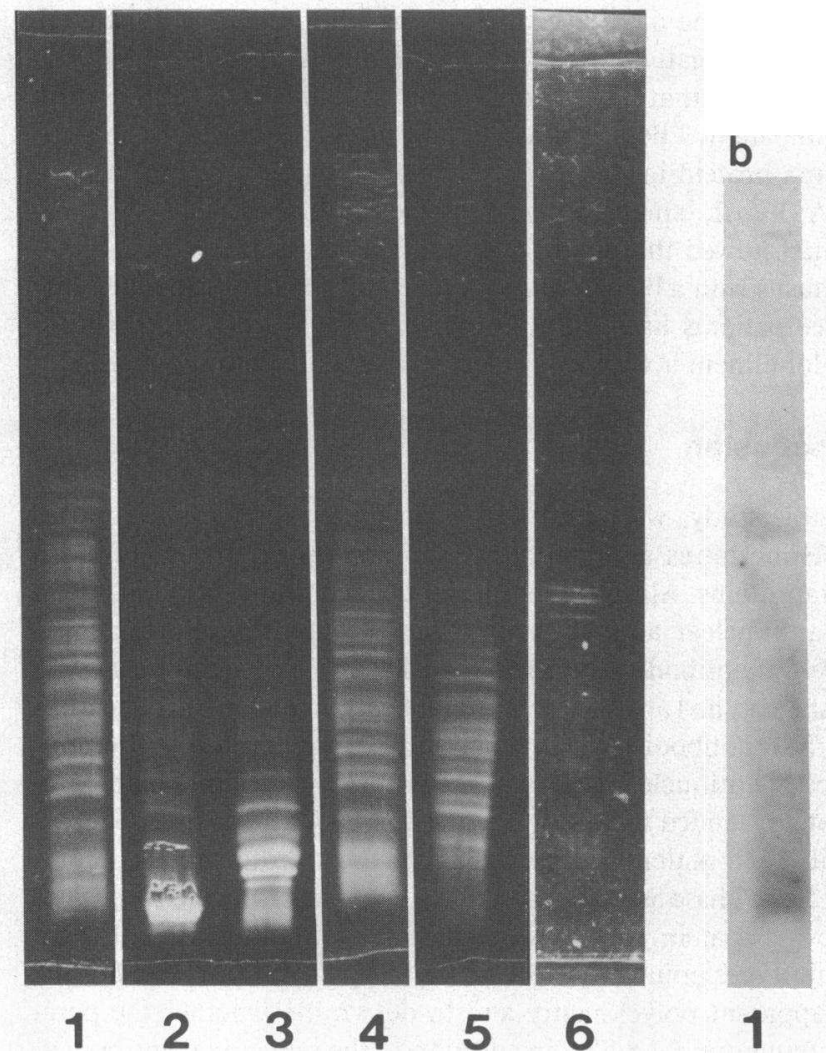

Figure 2. To determine anti-Ro/SSA binding, each serum was run on isoelectric focusing gels, precipitated using sodium sulfate, and exposed to ${ }^{125} \mathrm{I}$-labeled Ro/SSA. Photographs of total precipitated immunoglobulins, $(a)$, were compared to autoradiographs of the same gel, (b), to determine which serum components bound Ro/SSA. Samples

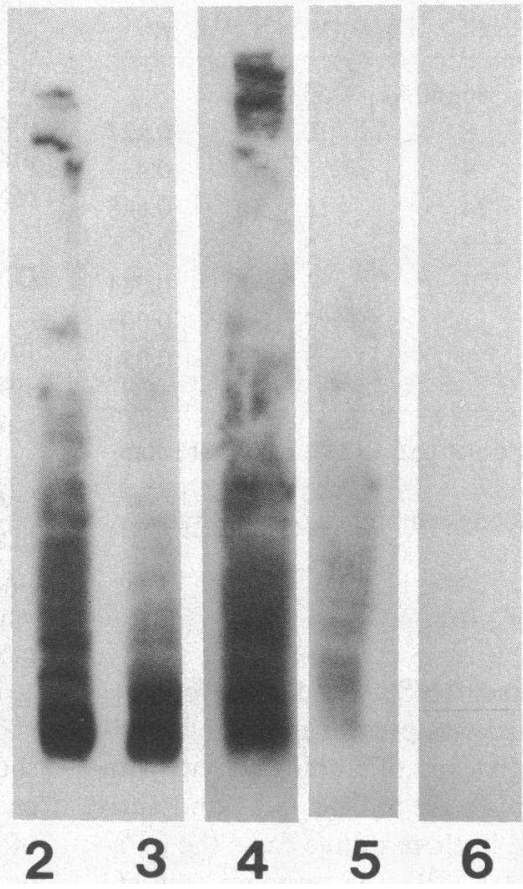

shown are: lane 1 -normal serum; lanes 2 and 3-SLE sera with paraproteins binding Ro/SSA (from patients 5 and 4, respectively, Table IV); lane 4-SLE serum containing a Ro/SSA precipitin but no paraprotein; lane 5-myeloma patient 3 with heterogeneous Ro/SSA binding; lane 6-myeloma sera with no anti-Ro/SSA binding. of these immunoglobulin types in normal serum (21). It is, therefore, presumed that the clones producing the monoclonal immunoglobulins randomly arise from cells participating in the normal immunoglobulin repertoire. By extension, one might suspect that the distribution frequency of paraprotein binding activities might be related to the proportional synthesis of antibodies to each specificity expressed in the repertoire. Our data support such a model since in each case where an Ro/SSA binding monoclonal immunoglobulin is present, there is also an antiRo/SSA polyclonal response, and even more relevant, no example has been found of an anti-Ro/SSA binding paraprotein in the absence of polyclonal anti-Ro/SSA. The classic hyperimmunization experiments in animals demonstrating that this maneuver at least transiently produces high concentrations of monoclonal antibodies support this model (22). Indeed, examples are known of homogeneous antibodies arising in patients with chronic infections in which the paraprotein binds an antigen from the infectious agent (1).

On the other hand, data showing an association of paraprotein type with serologic findings argues against the simple model presented above by suggesting that not all B cells have an equal risk of becoming a paraprotein producing clone. Specifically, sera with $\lambda$ light chain paraproteins tend to have more anti-Ro/ SSA and anti-La/SSB autoantibody than sera with $\kappa$ light chain paraproteins (despite approximately equivalent levels of $\kappa$ and $\lambda$ anti-Ro/SSA and anti-La/SSB antibodies in serum). Addi- tionally, paraprotein sera with multiple autoimmune reactivities are more likely to contain a $\lambda$ paraprotein than a $\kappa$ paraprotein (Table III and Results). The tendency toward $\lambda$ paraproteins in patients with rheumatoid arthritis and monoclonal gammopathy supports the validity of these observations (23). That the light chain paraprotein type is associated with anti-RNA protein binding activity provides additional evidence of subtle interrelationships between the factors responsible for autoimmune reactivity and those that generate at least a portion of the observed paraproteins. These experiments suggest that the risk for a B cell to develop into a paraprotein producing clone may vary to some extent depending upon the binding specificity of the immunoglobulins the individual produces. Indeed, transformation events in B cells are not always equivalent with respect to light chain type. In selected other lymphomas, $\lambda$ light chains are more frequent than expected $(24,25)$. Others have suggested that $\kappa$ and $\lambda$ expressing $B$ cells may belong to functionally distinct $B$ cell subsets (26-29) and our data would support this hypothesis. Our data suggest an interaction between autoimmune regulation and the propensity to generate a paraprotein producing $B$ cell clone.

There are a number of features that could be construed to favor the generation of Ro/SSA binding paraprotein clones. The autoimmune response to this autoantigen is often intense since a major proportion of the entire immunoglobulin present may bind this antigen $(5,6)$. Ro/SSA precipitins can be found in a 
wide variety of clinical circumstances in addition to patients with systemic lupus erythematosus and Sjögren's syndrome, including a small proportion of patients with other rheumatic diseases (30). Anti-Ro/SSA persists for extended periods and many individuals with this autoantibody are asymptomatic. For example, mothers of infants with complete congenital heart block, many of whom have no clinical disease, almost uniformly have high titers of anti-Ro/SSA (31-33). In addition, at least low levels of this autoantibody have been commonly found in normal donors (20), in normal relatives of patients with systemic lupus erythematosus (SLE) (34), and in the elderly (35).

Sjögren's syndrome patients often have anti-Ro/SSA and anti-La/SSB (6) and also have a tendency to develop B cell neoplasms (36-39). The most common lymphoma has IgM $\kappa$ cytoplasmic immunoglobulin $(40,41)$. In Sjögren's syndrome, autoimmune manifestations precede the appearance of a $\mathrm{B}$ cell lymphoma; therefore, this is another situation in which malignant transformation associated with autoimmunity shows a light chain preference in the expanding clone, albeit not the same light chain found in this study. That there may be a link between autoimmune stimulation and lymphoid transformation is also supported by the increased frequency of lymphoma in mouse models of SLE, chronic graft versus host disease, and rheumatoid arthritis (42-44). Interestingly, paraproteins of both light chain types, $27 \kappa$ and $17 \lambda$, have been reported in Sjögren's syndrome $(45,46)$. Evidence that some of these paraproteins have rheumatoid factor activity has been presented (45) but their activity against Ro/SSA and La/SSB is not known. Likewise, paraproteins are known to occur in systemic lupus erythematosus but their reactivities have not been characterized (47).

Anti-nRNP(Sm) is also commonly present at high concentrations in systemic lupus erythematosus, but it is rarely found in other rheumatic diseases. Even low levels are rare in normal individuals (20), and apparently anti-nRNP(Sm) is absent in patients with paraproteins. These differences between anti-Ro/ SSA and anti-nRNP(Sm) autoantibodies suggest that substantially different mechanisms are used to generate autoantibodies of the two specificities as has also been concluded from studies in normal donors (20). It has been proposed that the risk of developing a paraprotein clone may be related to anti-idiotypic antibody and there are data supporting this possibility (48-51).

The frequency of antinuclear antibodies in these paraprotein sera was very high, over $30 \%$, while none of the 39 normal controls had any antinuclear fluorescence. All sera were screened at a dilution of 1:250 to eliminate the background positivity seen in normal populations. The antinuclear antibody positives found here are therefore of potential importance and serve to screen for multiple autoimmune specificities in these sera. In the ELISA assays, paraprotein sera had significantly less than normal binding to specific autoantigens, suggesting that the antinuclear activity is not the result of an overall increase in autoimmune responses. From the variety of antinuclear fluorescent patterns seen with paraprotein sera, one would conclude that several autoantigen specificities are bound by the different positive paraprotein sera. It has not been determined whether such binding represents additional paraprotein specificities or simply polyclonal responses to several autoantigens, but the data serve to further establish the link between autoimmune reactivity and paraprotein production.

This study, therefore, has shown a higher proportion of paraprotein sera with autoantigen binding than has been pre- viously appreciated. High levels of polyclonal autoimmune activity may occur in paraprotein sera that does not necessarily involve the paraprotein itself. Anti-Ro/SSA, anti-La/SSB, and antinuclear antibodies commonly occur and are related in sera with paraproteins, while anti-nRNP autoantibodies are not found. In each serum where the autoimmune paraprotein binding specificity has been defined, polyclonal autoantibodies are also present. This and data relating anti-Ro/SSA and anti-La/ SSB autoimmune reactivity to paraprotein light chain type are consistent with a model in which these paraproteins not only arise from a previously established polyclonal response, but also certain structural properties of the immunoglobulin produced influence the likelihood of the B cell becoming a paraprotein producing clone.

\section{Acknowledgments}

We appreciate the help and support of Dr. Owen Fox, Ms. Kim Gaither, Ms. Mary Bittman, and Ms. Marianne Reichlin.

Supported by National Institutes of Health grants Am-34159, AM31133 , and AI-21568 by a clinical research center of the Arthritis Foundation, by the Veterans Administration, and by a Basil O'Connor starter grant (5-507) from the March of Dimes Birth Defects Foundation. Dr. Harley is an investigator of the Arthritis Foundation.

\section{References}

1. Seligman, M., and J. C. Brouet. 1973. Antibody activity of human myeloma globulins. Semin. Hematol. 10:163-177.

2. Latov, N., W. H. Sherman, R. Nemni, G. Galussi, J. S. Shyong, A. S. Penn, L. Chess, M. R. Olarte, L. P. Rowland, and E. G. Osserman. 1980. Plasma-cell dyscrasia and peripheral neuropathy with a monoclonal antibody to peripheral-nerve myelin. $N$. Engl. J. Med. 303:618-621.

3. Dighiero, F., B. Guibert, J. Fermand, P. Lymberi, F. Danon, and A. Avrameas. 1983. 36 human monoclonal immunoglobulins with antibody activity against cytoskeletal proteins, thyroglobulins and native DNA. Immunologic studies and clinical correlations. Blood. 62:264270.

4. Maddison, P. J., and M. Reichlin. 1977. Quantitation of precipitating antibodies to certain soluble nuclear antigens in SLE. Their contribution to hypergammaglobulinemia. Arthritis Rheum. 20:819-824,

5. Gaither, K. K., and J. B. Harley. 1985. Affinity purification and immunoassay of anti-Ro/SSA. Protides Biol. Fluids Proc. Colloq. 33: 413-416.

6. Harley, J. B., E. L. Alexander, W. B. Bias, O. F. Fox, T. T. Provost, M. Reichlin, H. Yamagata, and F. C. Arnett. 1986. Anti-Ro(SS-A) and anti-La(SS-B) in patients with Sjögren's syndrome. Arthritis Rheum. 29: 196-206.

7. Harley, J. B., M. R. Reichlin, F. C. Arnett, E. L. Alexander, W. B. Bias, and T. T. Provost. 1986. Gene Interaction at HLA-DQ enhances production in primary Sjögren's syndrome. Science (Wash. DC). 232:1145-1147.

8. Yamagata, H., J. B. Harley, and M. Reichlin. 1984. Molecular properties of the Ro/SSA antigen and ELISA for quantitation of antibody. J. Clin. Invest. 74:625-633.

9. Wolin, S. L., and J. A. Steitz. 1984. The Ro small cytoplasmic ribonuclear proteins: Identification of the antigenic protein binding site on the Ro RNAs. Proc. Natl. Acad. Sci. USA. 81:1996-2000.

10. Francoeur, A. M., E. K. L. Chan, J. I. Garrels, and M. B. Mathews. 1985. Characterization and purification of lupus antigen La, an RNA binding protein. Mol. Cell. Biol. 5:586-590.

11. Stefano, J. E. 1984. Purified lupus antigen La recognizes an oligoaridylate stretch common to the $3^{\prime}$ termini of RNA polymerase III transcripts. Cell. 36:145-154.

12. Reddy, R., P. Henning, E. M. Tan, and H. Busch. 1983. Iden- 
tification of a La protein binding site in a RNA polymerase III transcript (4.51 RNA). J. Biol. Chem. 258:8352-8356.

13. Lerner, M. R., and J. A. Steitz. 1979. Antibodies to small nuclear RNAs complexed with proteins are produced by patients with systemic lupus erythematosus. Proc. Natl. Acad. Sci. USA. 76:5495-5499.

14. Lerner, M. R., J. A. Boyle, S. M. Mount, S. L. Wolin, and J. A. Steitz. 1980. Are snRNPs involved in splicing? Nature (Lond.). 283:220224.

15. Mount, S. M., I. Petterson, M. Hinterberger, A. Karmas, and J. A. Steitz. 1983. The U1 small nuclear RNA-protein complex selectively binds a 5' splice site in vitro. Cell. 33:509-518.

16. Harley, J. B., H. Yamagata, and M. Reichlin. 1984. Anti-La/ SSB antibody is present in some normal sera and is coincident with antiRo/SSA precipitins in systemic lupus erythematosus. J. Rheumatol. 11: 309-314.

17. Tan, E. M., A. S. Cohen, J. F. Fries, A. T. Masi, D. J. McShane N. F. Rothfield, J. G. Schaller, N. Talal, and R. J. Winchester. 1982. The 1982 revised criteria for the classification of systemic lupus erythematosus. Arthritis Rheum. 25:1271-1277.

18. Harley, J. B., M. O. Rosario, H. Yamagata, O. F. Fox, and E. Koren. 1985. Immunologic and structural studies of the lupus/Sjögren's syndrome autoantigen, La/SSB, with a monoclonal antibody. J. Clin. Invest. 76:801-806.

19. Harley, J. B. 1985. Autoantibodies in Sjögren's syndrome: comparison of autoantibody determination methods show that antinuclear antibody and rheumatoid factor are associated with Ro/SSA precipitin formation. Protides Biol. Fluids Proc. Colloq. 33:343.

20. Gaither, K. K., O. F. Fox, H. Yamagata, M. J. Mamula, M. Reichlin, and J. B. Harley. 1987. Implications of anti-Ro/SSA autoantibody in normal sera for autoimmunity. J. Clin. Invest. 79:841-846.

21. Kunkel, H. G. 1965. Myeloma proteins and antibodies. Harvey Lect. Ser. 59:219-242.

22. Krause, R. M. 1970. The search for antibodies with molecular uniformity. Adv. Immunal. 12:1-56.

23. Youinou, P., P. LeGoff, J. C. Reiner, D. Hurez, P. Miossec, and W. J. W. Morrow. 1983. Relationship between rheumatoid arthritis and monoclonal gammapathy. J. Rheumatol. 10:210-215.

24. Stein, H., J. Gerdes, and D. Y. Mason. 1982. The normal and malignant germinal centre. Clin. Haematol. 11:531-559.

25. Swerdlow, S. H., J. A. Habeshaw, L. G. Murray, H. S. Dhaliwal, T. A. Lister, and A. G. Stansfeld. 1983. Centrocytic lymphoma: a distinct clinicopathologic and immunologic entity. A multiparameter study of 18 cases at diagnosis and relapse. Am. J. Pathol. 113:181-197.

26. Jack, R. S., T. Imanishi-Kari, and K. Rajewsky. 1977. Idiotypic analysis of the response of C5BL/6 mice to the (4-hydroxy-3-nitrophenyl)acetyl group. Eur. J. Immunol. 8:559-565.

27. Haughton, G., L. L. Lanier, and G. F. Babcock. 1978. The murine kappa light chain shift. Nature (Lond.). 275:154-157.

28. Burkly, L. C., R. Zaugg, H. N. Eisen, and H. H. Wortis. 1982 Influence of the nude and $\mathrm{x}$-linked immune deficiency genes on expression of kappa and lambda light chains. Eur. J. Immunol. 12:1033-1039.

29. Nishikawa, S.-I., T. Kina, J.-I. Gyotoku, and Y. Katsura. 1984. High frequency of $\lambda$ gene activation in bone marrow pre-B cells. J. Exp. Med. 159:617-622.

30. Bernstein, R. M., C. C. Bunn, G. R. U. Hughes, A. M. Francoeur, and M. B. Mathews. 1984. Cellular protein and RNA antigens in autoimmune disease. Mol. Biol. Med. 2:105-120.

31. Scott, J. S., P. J. Maddison, P. B. Taylor, E. Esscher, O. Scott, and R. P. Skinner. 1983. Connective-tissue disease, antibodies to ribonucleoprotein and congenital heart block. N. Engl. J. Med. 309:209212.

32. Watson, R., A. T. Lane, N. K. Barnett, W. B. Bias, F. C. Arnett, and T. T. Provost. 1984. Neonatal lupus erythematosus. A clinical, serological and immunogenetic study with review of the literature. Medicine. 63:362-378.

33. Provost, T. T., R. Watson, K. Gaither, and J. B. Harley. 1986. The neonatal lupus syndrome. $J$. Rheumatol. In press.

34. Lehman, T. J. A., V. Hanson, N. Zvaifler, G. Sharp, and M. Alspaugh. 1984. Antibodies to nonhistone nuclear antigens and antilymphocyte antibodies among children and adults with systemic lupus erythematosus and their relations. J. Rheumatol. 11:644-647.

35. Strickland, R. W., J. T. Tesar, B. H. Berne, B. R. Hobbs, D. R. Moeller, D. D. Richardson, D. M. Lewis, and R. C. Welton. 1984. The prevalence of Sjögren's syndrome and associated diseases in an elderly population. Arthritis Rheum. 27:S45.

36. Talal, N., and J. J. Bunim. 1964. The development of malignant lymphoma in the course of Sjögren's syndrome. Am. J. Med. 36:529540.

37. Talal, N., L. Sokoloff, and W. F. Barth. 1967. Extrasalivary lymphoid abnormalities in Sjögren's syndrome (reticulum cell sarcoma, "pseudolymphoma," macroglobulinemia). Am. J. Med. 43:50-65.

38. Anderson, L. G., and N. Talal. 1972. The spectrum of benign to malignant lympho-proliferation in Sjögren's syndrome. Clin. Exp. Immunol. 10:199-211.

39. Kassan, S. S., T. L. Thomas, H. M. Montsopoulos, R. Hoover, R. P. Kimberly, D. R. Budman, S. Costa, J. L. Decker, and T. M. Chused. 1978. Increased risk of lymphoma in sicca syndrome. Ann. Intern. Med. 89:888-892.

40. Zulman, J., R. Jaffe, and N. Talal. 1978. Evidence that the malignant lymphoma of Sjögren's syndrome is a monoclonal B-cell neoplasm. N. Engl. J. Med. 299:1215-1220.

41. Faguet, G. B., H. H. Webb, J. F. Agee, W. B. Ricks, and A. H. Sharbaugh. 1978. Immunologically diagnosed malignancy in Sjögren's syndrome. Am. J. Med. 65:424-429.

42. Warner, N. L. 1977. Genetic aspects of immunologic abnormalities in New Zealand mouse strains. Arthritis Rheum. 21:5106-5112.

43. Tateno, M., N. Kondo, T. Itoh, and T. Yoshiki. 1985. Autoimmune disease and malignant lymphoma associated with graft-versushost disease in mice. Clin. Exp. Immunol. 62:535-544.

44. Hakulinen, T. 1985. Rheumatoid arthritis and cancer studies based on linking autoimmune registries in Finland. Am. J. Med. 78(1A): 29-32.

45. Sugai, S., S. Shimizu, Y. Hirose, T. Tahiguchi, S. Konda, and H. Tamano. 1985. Monoclonal gammopathies in Japanese patients with Sjögren's syndrome. J. Clin. Immunol. 5:90-101.

46. Moutsopoulos, H. M., R. Costello, A. A. Drosos, A. K. Mavridis, and H. M. Papadopoulos. 1985. Demonstration and identification of monoclonal proteins in the urine of patients with Sjögren's syndrome. Ann. Rheum. Dis. 44:109-112.

47. Rubin, L., M. B. Urowitz, and W. Pruzunski. 1984. Systemic lupus erythematosus with paraproteinemia. Arthritis Rheum. 27:638644.

48. Plotz, P. H. 1983. Autoantibodies are anti-idiotype antibodies to antiviral antibodies. Lancet. ii:824-826.

49. Wassermon, N. H., A. S. Penn, P. I. Friemuth, N. Treptow, S. Wentzel, W. L. Cleveland, and B. F. Erlanger. 1982. Anti-idiotypic route to anti-acetyl choline receptor antibodies and experimental myesthenia gravis. Proc. Natl. Acad. Sci. USA. 79:4810-4814.

50. Islam, M. N., B. M. Pepper, R. Broines-Urboina, and N. R. Farid. 1983. Biological activity of anti-thyrotropin anti-idiotypic antibody. Eur. J. Immunol. 13:57-63.

51. Zouali, M., J.-M. Fine, and A. Equem. 1984. A human monoclonal IgG1 with anti-idiotypic activity against anti-human thyroglobulin autoantibody. J. Immunol. 133:190-194. 